\title{
Violências cruzadas e obstáculos para a proteção de refugiados LGBTI
}

\author{
Stéphany Brum ${ }^{1}$
}

ISSN: 2350-0844

п. 12, v. I поv.2019-abr.2020 р. 38-53.

RESUMO: As relações sexuais consensuais entre adultos do mesmo sexo são criminalizadas em quase 70 países, com punições que podem variar entre o encarceramento e a pena de morte. No que diz respeito à população trans, a organização não governamental (ONG) Transgender Europe contabilizou 2.892 assassinatos de pessoas não cisgêneras em 74 países entre janeiro de 2008 e setembro de 2018. Não obstante, foi apenas partir dos anos 2000 que a comunidade de lésbicas, gays, bissexuais, transexuais, travestis e intersexuais (LGBTI) passou a figurar nos estudos migratórios, principalmente com o debate acerca do sexilio, isto é, quando indivíduos de gênero e/ou sexualidade dissidentes deixam seus lares em busca de uma vida plena e segura. Nesse sentido, este trabalho consiste em uma tentativa de extrapolar o debate puramente teórico e compreender os desafios enfrentados por essa população desde seus lugares de origem até o processo de integração nos países de destino. A importância deste estudo justifica-se por sua contribuição para o debate já existente na academia sobre o refúgio de indivíduos LGBTI e, além disso, por evidenciar a necessidade de criação de novas estratégias, bem como de políticas públicas por parte dos Estados, que tornem possível o acolhimento mais seguro e humano dessa população.

PALAVRAS-CHAVE: Migrações internacionais. Refúgio. LGBTI. Sexílio.

Abstract: Consensual sex between same-sex adults is criminalized in almost 70 countries, with punishments ranging from incarceration to death penalty. When it comes to the transgender community, the nongovernmental organization (NGO) Transgender Europe recorded 2,892 murders of non-cisgender people in 74 countries between January 2008 and September 2018. Nevertheless, it was not until the 2000s that the lesbian, gay, bisexual, transgender and intersex community (LGBTI) came to feature in migration studies, especially with the debate about sexile, that is, when individuals of dissenting gender and/or sexuality leave their homes in search of a full and safe life. This study is thus an attempt to overcome the purely theoretical debate and understand the challenges faced by this population from their place of origin to the process of integration in destination countries. The importance of this study is justified by its contribution to the debate that already exists within the academy about the refuge of LGBTI individuals and, furthermore, because it highlights the need to create new strategies as well as public policies by the states that make a safer and more humane reception possible for this community.

Keywords: International migrations. Refuge. LGBTI. Sexile.

Resumen: Se criminalizan las relaciones sexuales consentidas entre adultos del mismo sexo en casi 70 países con castigos, que van desde el encarcelamiento hasta la pena de muerte. Con relación a la población transgénero, la ONG Transgender Europe contabilizó 2.892 asesinatos de personas no cisgénero en 74 países entre enero de 2008 y septiembre de 2018. Sin embargo, la comunidad LGBTI solamente a partir de la década de 2000 fue tema de estudios migratorios, especialmente de debates sobre sexilio, es decir, cuando las personas de género y/o sexualidad disidentes abandonan sus hogares en busca de una vida plena y segura. En este sentido, este trabajo es un intento de extrapolar el debate puramente teórico y comprender los desafíos que enfrenta esta población desde su lugar de origen hasta el proceso de integración en los países de destino. La importancia de este estudio se justifica por su contribución al debate ya existente en la academia sobre el refugio de las personas LGBTI y, además, destaca la necesidad de la creación de nuevas estrategias, así como de políticas públicas por parte de los estados, que hagan posible la recepción más segura y humana de esta población.

Palabras clave: Migraciones internacionales. Refugio. LGBTI. Sexilio.

\footnotetext{
${ }^{1}$ Mestranda no Programa de Pós-Graduação em Ciência Política da Universidade Federal do Estado do Rio de Janeiro (Unirio). E-mail: brumstephany@gmail.com 


\title{
1. Introdução
}

Carlos Fouquet (1974, p. 11) foi categórico ao afirmar que "a história da humanidade é a história das migrações e de suas consequências". Movimentos migratórios datam do período pré-histórico e, desde o século XIX, existem estudos voltados para esse fenômeno, ainda que a partir de uma perspectiva puramente econômica e com atenção direcionada, principalmente, aos indivíduos que migravam de forma voluntária. (CASTLES; MILLER, 2004; KOSER, 2007) Não obstante, com o processo de expansão imperialista e o avanço do capitalismo, as teorias clássicas se mostraram incapazes de abordar a temática em sua totalidade, sendo necessário um enfoque multidisciplinar e que leve em consideração as diferentes expressões de mobilidade humana, bem como suas motivações e circunstâncias. (CASTLES, 2010)

Dessa forma, tendo em vista os diversos marcadores sociais envolvidos ao longo do processo migratório, Magliano (2015) defende a adoção de uma perspectiva interseccional no estudo do fenômeno a fim de compreendê-lo para além da vivência do homem branco, heterossexual e de classe social privilegiada. Conforme a autora:

\begin{abstract}
Nas migrações internacionais, as classificações de gênero, classe, nacionalidade, raça, etnicidade, faixa etária, condição migratória e religião podem influenciar diretamente na vida cotidiana de mulheres e homens e influenciar de maneira determinante seu acesso a direitos e oportunidades, assim como em situações de privilégios ou de exclusão que delas se derivam. (MAGLIANO, 2015, p. 700, tradução nossa)²
\end{abstract}

Além dos marcadores já citados, orientação sexual e/ou identidade de gênero também podem servir como motivações para migrações, seja de forma voluntária ou forçada. (ANDRADE, 2017; REZENDE, 2018) A criminalização de relações sexuais consensuais entre adultos do mesmo sexo está presente em quase 70 países, com punições que podem variar entre o encarceramento e a pena de morte. (THE INTERNATIONAL LESBIAN, GAY, BISEXUAL, TRANS AND INTERSEX ASSOCIATION [ILGA], 2019) No que diz respeito especificamente à população trans, a organização não governamental (ONG) Transgender Europe (2018) contabilizou 2.892 assassinatos de pessoas não cisgêneras em 74 países entre janeiro de 2008 e setembro de 2018. Perseguições como essas levaram o Alto Comissariado

\footnotetext{
${ }^{2}$ No original: "En las migraciones internacionales, las clasificaciones de género, clase, origen nacional, raza, etnicidad, edad, condición migratoria y religión pueden incidir directamente en la vida cotidiana de mujeres y varones e influir de manera determinante en su acceso a derechos y oportunidades, así como en las situaciones de privilegio o de exclusión que de ellas se derivan." (MAGLIANO, 2015, p. 700) 
das Nações Unidas para os Refugiados (Acnur) a recomendar, desde 2002, que os Estados acolham membros da comunidade de lésbicas, gays, bissexuais, transexuais e intersexuais (LGBTI) como refugiados. (ANDRADE, 2017)

Mesmo diante desse cenário, essa população só passou a figurar nos estudos migratórios a partir do século XXI, principalmente com o debate entre La Fountain-Stokes (2004), Binnie (2004), Eribon (2008) e Mogrovejo (2016 apud ANDRADE, 2017) sobre o que foi classificado como sexílio, isto é, quando indivíduos de gênero e/ou sexualidade dissidentes deixam seus Estados de origem em busca de uma vida plena e segura.

No Brasil, foi apenas a partir de 2012 que essa temática passou a ser investigada pela comunidade acadêmica, com trabalhos de Oliva (2012), sobre as Minorias sociais enquanto "grupo social" e o reconhecimento do status de refugiado no Brasil, e de Muller (2012), sobre refugiados homossexuais de origem iraniana. Posteriormente, mais pesquisadores começaram a explorar e enriquecer o debate, como Sobreira $(2014 ; 2015)$, Nascimento (2015; 2016; 2018), Silva (2015; 2016; 2017), Mendes (2016; 2017), Mendes e Gorich (2016a; 2016b; 2016c; 2016d), Fernandes (2016), França e Oliveira (2016), França (2015; 2017), Andrade (2015a; 2015b; 2016a; 2016b; 2016c; 2016d; 2017), Rezende (2018), Fraiha (2018), Theodoro e Cogo (2019) e Santos (2019).

Em relação aos estudos que exploram o tema do refúgio de pessoas LGBTI, principalmente nas áreas do Direito e das Relações Internacionais, Andrade (2017, p. 219) afirma que "no geral, não se extrapola o âmbito legal, não se analisam as experiências desses/as sujeitos/as uma vez que se encontram no Brasil". Nesse sentido, o propósito deste trabalho consiste em uma tentativa de extrapolar o debate puramente teórico e compreender os desafios enfrentados por essa população desde seus lugares de origem até o processo de integração nos países de destino.

A importância da pesquisa justifica-se por sua contribuição para o debate já existente na academia acerca do refúgio de indivíduos LGBTI e, além disso, por evidenciar a necessidade de criação de novas estratégias, bem como de políticas públicas por parte dos Estados, que tornem possível o acolhimento mais seguro e humano dessa população. 


\section{Perseguição em função de orientação sexual e/ou identidade de} gênero

Aproximadamente 740 milhões de pessoas eram migrantes dentro de seus próprios países em 2009 e, em 2015, cerca de 244 milhões eram migrantes internacionais. (ORGANIZAÇÃO INTERNACIONAL PARA AS MIGRAÇÕES [OIM], 2018) Esses fluxos migratórios têm sido facilitados, principalmente a partir das décadas de 1970 e 1980, em grande parte graças ao desenvolvimento dos meios de comunicação e transporte, cada vez mais acessíveis. Assim, a mobilidade humana pode manifestar-se de diferentes maneiras, das quais nem todas são voluntárias. (WIHTOL DE WENDEN, 2016)

Graves violações de direitos humanos, perseguições a certos grupos sociais, desastres naturais e escalada da pobreza, da desigualdade social e de conflitos são algumas das razões que podem levar alguém a migrar contra sua própria vontade. (JUBILUT; APOLINÁRIO, 2010) Dessa forma, interessa a este trabalho destacar as migrações forçadas de indivíduos de gênero e/ou sexualidade dissidentes.

A noção de gênero pode ser entendida como um "conjunto de características comportamentais e psicológicas socialmente construídas e associadas ao masculino e ao feminino". (GARDNER, 2006, p. 98-99) Esse termo passou a ser adotado por autoras feministas a partir da década de 1960, com o intuito de contestar a ideia do determinismo biológico ao afirmarem que o gênero não é consequência do sexo, e sim do processo de socialização do indivíduo. (BUTLER, 2015; GARDNER, 2006) Ademais, o gênero funciona como um regulador das relações sociais, visto que, conforme Saffioti (2004a, p. 45), trata-se de "uma gramática sexual, regulando não apenas relações homem-mulher, mas também relações homem-homem e relações mulher-mulher”.

Essa gramática sexual responsável por controlar as relações entre os indivíduos é caracterizada pelo binarismo de gênero, ou seja, impõe papéis considerados femininos para mulheres, e masculinos para homens. Assim, pessoas capazes de manter uma concordância entre o sexo, o gênero, a prática sexual e, por fim, o desejo sexual possuem identidades de gênero inteligíveis que, segundo Butler (2015), constituem uma matriz socialmente construída e imposta de inteligibilidade de gênero. Contudo, a autora defende a existência de outras matrizes, isto é, que não mantêm coerência entre os quatro elementos citados e que, por esse 
motivo, são rejeitadas ao não seguirem o padrão culturalmente determinado. (BUTLER, 2015; SAFFIOTI, 2004b)

Outra complexidade inerente ao gênero refere-se ao fato de que esse elemento não deve ser analisado de forma isolada. É preciso ter em mente que os indivíduos são possuidores de outras identidades sociais, como classe social e raça/etnia, que os tornam plurais. Essas identidades encontram-se entrelaçadas de forma que a vivência de cada uma delas seja distinta para cada indivíduo, isto é, pode levar uma pessoa a experimentar de maneira mais ou menos intensa os problemas decorrentes do sistema patriarcal. (GARDNER, 2006; SAFFIOTI, 2004a, 2004b; SAFFIOTI; MUÑOZ-VARGAS, 1994)

Assim, são muitos os Estados que ainda aplicam severas punições aos indivíduos que não se encaixam no padrão imposto por esse sistema. Segundo o último relatório apresentado pela ILGA, dos quase 70 países que criminalizam as relações sexuais consensuais entre adultos do mesmo sexo, 11 adotam a pena de morte e quase 60 podem aplicar sentenças que variam entre poucos anos de encarceramento até a prisão perpétua. Ademais, 55 Estados, apesar de não criminalizarem a prática, não oferecem qualquer tipo de proteção à população LGBTI. (ILGA, 2019)

Em relação à comunidade trans, para além do grande número de assassinatos já citado anteriormente, o não reconhecimento pelo Estado e pela sociedade da identidade de gênero de um indivíduo pode levá-lo a encontrar grandes desafios ao longo de sua vida em diferentes âmbitos. A fim de ilustrar os impactos causados por essa invisibilidade, pode-se citar um estudo realizado na Argentina pela Fundación Huésped (2014), em parceria com a Associação de Travestis, Transexuais e Transgêneros da Argentina, para compreender os impactos da aprovação da Lei de Identidade de Gênero no país.

O estudo mostrou que $41,2 \%$ das mulheres trans e 58,2\% dos homens trans evitavam buscar atendimento em postos de saúde devido ao medo de sofrerem com a discriminação antes da Lei de Identidade de Gênero. Além disso, 48,8\% das mulheres e 47,4\% dos homens não conseguiram seguir com seus estudos. No que diz respeito ao mercado de trabalho formal, o estudo aponta que 54,6\% das mulheres entrevistadas já perderam oportunidades de emprego por serem trans, o que pode explicar a grande quantidade de travestis, transexuais e transgêneros no mercado da prostituição. (FUNDACIÓN HUÉSPED, 2014) Pode-se afirmar, portanto, que: 
A realidade desse coletivo está marcada por um contexto de perseguição, exclusão e marginalização. As pessoas trans não gozam da igualdade de oportunidades e de tratamento em nenhum âmbito da vida social e institucional; a maioria delas vive em extrema pobreza, privadas de direitos econômicos, políticos, sociais e culturais. Desde muito pequenas, as pessoas trans são expulsas de seus lares e do âmbito escolar, restando como única alternativa de subsistência o exercício da prostituição. (MOURATIAN, 2011, p. 7, tradução nossa) ${ }^{3}$

Para além da esfera normativa, mesmo em países onde não são criminalizados, membros da comunidade LGBTI ainda sofrem violência física, verbal e psicológica por parte da sociedade local - e até mesmo da própria família. Não são raros os casos de mulheres lésbicas e bissexuais que são estupradas em tentativas de reverter suas sexualidades, nem de jovens que são expulsos de casa ao se assumirem não heterossexuais e/ou não cisgêneros. Até mesmo pessoas intersexuais podem sofrer perseguições em algumas culturas ou religiões por serem entendidas como alguma espécie de bruxaria. (NASCIMENTO, 2018)

Assim, mesmo com a existência de um sistema de proteção aos direitos humanos e o debate acerca da diversidade sexual e de gênero cada vez mais presente na agenda internacional, muitos Estados ainda não possuem políticas públicas para garantir o devido reconhecimento e a proteção dessa categoria. Muitos desses indivíduos, portanto, se veem obrigados a deixar suas cidades de origem, e até mesmo seus países, em busca de uma vida mais plena e segura. É nesse contexto que a seção seguinte tratará do sistema de proteção aos dissidentes sexuais e/ou de gênero que solicitam refúgio.

\section{O refúgio em função de orientação sexual e/ou identidade de} gênero

Segundo relatório publicado pelo Acnur (2018), ao menos 70,8 milhões de indivíduos são vítimas de deslocamento forçado pelo mundo atualmente, sendo 25,9 milhões refugiados e 3,5 milhões solicitantes de asilo. Inicialmente elaborada com o objetivo de proteger vítimas de perseguições políticas no contexto europeu, a definição de refúgio passou por uma série de adaptações até ser oficialmente estabelecida a partir da

\footnotetext{
3 No original: "La realidad de este colectivo está atravesada por um contexto de persecución, exclusión y marginación. Las personas trans no gozan de igualdad de oportunidades y de trato en ningún ámbito de la vida social e institucional; la mayoría de ellas vive en extrema pobreza, privadas de derechos económicos, políticos, sociales y culturales. Desde muy pequeñas las personas trans son expulsadas de sus hogares y del ámbito escolar, quedándoles como única alternativa de subsistencia el ejercicio de la prostitución.” (MOURATIAN, 2011, p. 7) 
Convenção Relativa ao Estatuto dos Refugiados de 1951 (JUBILUT; APOLINÁRIO, 2010), que considera refugiada qualquer pessoa que:

[...] temendo ser perseguida por motivos de raça, religião, nacionalidade, grupo social ou opiniões políticas, se encontra fora do país de sua nacionalidade e que não pode ou, em virtude desse temor, não quer valer-se da proteção desse país, ou que, se não tem nacionalidade e se encontra fora do país no qual tinha sua residência habitual em consequência de tais acontecimentos, não pode ou, devido ao referido temor, não quer voltar a ele. (ORGANIZAÇÃO DAS NAÇÕES UNIDAS, 1951)

Esse sistema de proteção passou por novos ajustes ao longo dos anos posteriores, principalmente com o Protocolo de 1967, que tornou o refúgio universal, e a elaboração de documentos regionais que ampliaram o conceito em função de contextos próprios, como a Convenção da Organização de Unidade Africana de 1969 e a Declaração de Cartagena de 1984. Ademais, cada país possui liberdade para criar dispositivos para além daqueles previstos em tratados internacionais. (JUBILUT; APOLINÁRIO, 2010; NASCIMENTO, 2018) Assim, são mais variadas as razões pelas quais um indivíduo pode solicitar o status de refugiado hoje e, de acordo com Jubilut e Apolinário (2010, p. 283), esses "são os migrantes forçados que contam com o sistema mais completo de proteção".

No que tange especificamente à questão de gênero, desde 2002 o Acnur a entende enquanto um elemento propulsor de perseguições e, dessa forma, reconhece a existência de vítimas em virtude de sexualidade e práticas sexuais. (ACNUR, 2002) A sigla LGBTI foi usada pela primeira vez em 2008, quando a organização apresentou um documento voltado especificamente para a temática do refúgio em função de orientação sexual e/ou igualdade de gênero (ACNUR, 2008) e, em 2012, o substituiu pelo intitulado Diretrizes de proteção internacional $n^{\circ}$ 09: solicitações de refúgio baseadas na orientação sexual elou identidade de gênero no contexto do artigo 1A(2) da Convenção de 1951 elou Protocolo de 1967 relativo ao Estatuto dos Refugiados. (ACNUR, 2012) Em todas essas ocasiões, vítimas desse tipo de violência foram entendidas como parte de um grupo social próprio que devem ter suas solicitações de asilo aceitas. (ANDRADE, 2017)

Atualmente, cerca de 40 Estados concedem refúgio à essa comunidade, número crescente desde a década de 1980. (ACNUR, 2018; ANDRADE, 2017) No Brasil, contabilizou-se um total de 369 solicitações de asilo em função de orientação sexual e/ou identidade de gênero entre 2010 e 2018. A maior parte dessa população é composta por 
homens gays de origem africana, sendo a Nigéria o principal país de origem, seguida de Gana, Camarões e Serra Leoa, entre outros. Também é importante destacar que nem todas as pessoas que solicitam refúgio por essa razão se identificam enquanto LGBTI, podendo sofrer perseguição pelo simples fato de serem ativistas em defesa dessa população. (ACNUR, 2018)

Para além dessas perseguições em seus próprios países, sujeitos de sexualidade e/ou gênero dissidentes também podem ter que enfrentá-las ao chegar em um novo destino. Em muitos casos, por falta de onde se estabelecer, migrantes, refugiados ou não, ficam hospedados em abrigos financiados por ONGs ou até mesmo pelo próprio Estado. No entanto, nem sempre os funcionários responsáveis pelo atendimento são preparados para lidar com a população LGBTI ou para compreender suas particularidades. (ANDRADE, 2016a) Além disso, muitas dessas organizações responsáveis pelo acolhimento são religiosas, o que pode dificultar ainda mais a expressão da identidade sexual e a narração da própria história de vida. Esse fato é evidenciado pela coordenadora de uma ONG em entrevista a Andrade (2016a), ao narrar o caso de um refugiado de origem africana:

A gente já teve um caso no final do ano passado [2013], início desse ano, de um refugiado que estava fugindo por isso [por ser gay] e aí a gente precisou da ajuda de um tradutor, uma pessoa do país dele, e quando ele começou a relatar, o africano, o refugiado que tava acompanhando, olhou e disse: “ah, ele tá pedindo refúgio porque ele é "viado"”. E ele começou a falar... A gente não entendia o que ele tava dizendo, mas percebeu que ali rolou um conflito, porque a pessoa descobriu que ele era [gay]. A gente tá tentando aprender como lidar com esses casos. (ANDRADE, 2016a, p. 15)

Diante de cenários como esse, o Acnur divulgou em 2011 uma espécie de guia básico voltado para organizações que podem vir a trabalhar com essa categoria. Assim, algumas orientações destacadas pela organização são: conscientização e treinamento dos funcionários acerca da proteção de pessoas LGBTI, bem como suas especificidades; o envolvimento de indivíduos da comunidade LGBTI nos processos de tomada de decisão; e a criação de espaços seguros de modo que o alojamento seja cada vez mais seguro e adequado, entre muitas outras. (ACNUR, 2011)

As violências, no entanto, nem sempre se encerram com estratégias desse tipo, visto que, por muitas vezes, a discriminação pode partir da própria população local e até mesmo de outros refugiados que se hospedam nos mesmos abrigos.

Periódicus, Salvador, n. 12, v.1, nov.2019-abr.2020 - Revista de estudos indisciplinares em gêneros e sexualidades Publicação periódica vinculada ao Núcleo de Pesquisa NuCuS, da Universidade Federal da Bahia - UFBA ISSN: 2358-0844 - Endereço: http://www.portalseer.ufba.br/index.php/revistaperiodicus 


\section{Violências cruzadas no acolhimento de pessoas LGBTI}

São conhecidas as dificuldades enfrentadas por solicitantes de refúgio ao longo do processo de integração no país destino. Não são raros os casos de pessoas que são vítimas de xenofobia, principalmente aquelas de classes sociais mais baixas, por parte da população local. (FÉLIX; COSTA, 2018) Soma-se a isso a LGBTIfobia, e o que se percebe é um tipo de violência interseccional que, para além do status de migrante, envolve classe social, sexualidade e identidade de gênero.

O Brasil, por exemplo, apesar de adotar uma postura favorável à concessão de refúgio para esse grupo desde 2002 (ANDRADE, 2017), revela uma grande contradição ao apresentar altos índices de violência contra a população LGBTI, sendo o país que mais mata travestis e transexuais no mundo. (TRANSGENDER EUROPE, 2018) Em abril de 2019, o presidente Jair Bolsonaro se mostrou pouco receptivo ao que classificou como "turismo gay", afirmando que "o Brasil não pode ser um país do mundo gay, de turismo gay. Temos famílias". (BOLSONARO..., 2019) Também no primeiro semestre desse mesmo ano, uma mulher trans brasileira teve sua solicitação de asilo aceita pelo governo italiano. Conforme a comissão responsável por julgar o caso:

\footnotetext{
Apesar de ter dado passos importantes em termos de proteção jurídica contra a discriminação baseada na orientação sexual e na identidade de gênero, o Estado [brasileiro] nem sempre se demonstrou capaz ou disposto a proteger as pessoas LGBTI de agressões e perseguições, seja por causa da cultura machista do país, seja pela forte influência religiosa no discurso público. (ANSA, 2019)
}

Esse cenário de retração de conquistas sociais não é uma singularidade brasileira. Com o fim da onda rosa na América Latina e a ascensão de movimentos e governos conservadores, muitas vezes munidos de discursos religiosos, a região têm expulsado cada vez mais dissidentes sexuais e/ou de gênero. (ANARTE, 2019) Segundo o relatório El prejuicio no conoce fronteras (SIN VIOLENCIA LGBTI, 2019), divulgado em agosto de 2019, foram 1.292 homicídios de pessoas LGBTI entre 2014 e 2019 em países latinoamericanos e do Caribe, sem contar o Brasil.

Mesmo diante desse cenário, o Brasil ainda é considerado um dos destinos possíveis para solicitação de refúgio por parte dessa população. Isso se deve ao processo de politização e securitização da temática de migrações na agenda internacional, 
principalmente a partir dos atentados terroristas ocorridos em 11 de setembro de 2001. Assim, países que antes eram considerados como destinos tradicionais, principalmente por pessoas do continente africano, têm dificultado cada vez mais a entrada de migrantes e refugiados que não os interessam economicamente. (ANDRADE, 2017; CASTLES; MILLER, 2004) O Brasil, então, se torna uma possibilidade, visto que ao menos não criminaliza suas vivências e conta com alguns dispositivos legais que visam protegê-las, como a recente decisão do Supremo Tribunal Federal a favor da criminalização da LGBTIfobia. (BARIFOUSE, 2019)

Para além da discriminação por parte da população local, esses indivíduos também acabam enfrentando violências de outros refugiados, muitas vezes conterrâneos, pelo fato de não serem heterossexuais ou cisgêneros. Essa situação torna hostil a vivência em abrigos comuns, principalmente para aqueles que não performam masculinidade (no caso dos homens) ou feminilidade (no caso das mulheres). Também ao conceder entrevista a Andrade (2016a), uma assistente social narrou a experiência de uma refugiada transexual que não aguentou permanecer em um desses lugares. Segundo a profissional, a mulher:

Ficou uns 15 dias. E tinha uma coisa assim do tipo, olhavam para ele com olhar de desdém o tempo todo. E ele se aproximava mais das meninas. Usava saia, batom, peruca, tinha a sobrancelha fininha. Às vezes ele vinha aqui, queria falar alguma coisa, despistava, depois já começava a chorar... Era isso, né. A represália. Porque estava muito contente em ter sido acolhido, estava muito bem, e acho que não suportou ficar mais tempo aqui justamente por isso. Acabou ficando duas semanas e foi embora. Ele sofreu muito preconceito, muito. (ANDRADE, 2016a, p. 15)

Dessa forma, organizações da sociedade civil têm criado interessantes estratégias para a proteção de refugiados LGBTI. Destaca-se aqui, portanto, a abertura de centros de acolhida voltados especificamente para essa população, como é o caso do abrigo alemão mantido pela ONG Schwulenberatung Berlin e a Casa Miga, localizada em Manaus.

\section{Centros de acolhida para refugiados LGBTI}

Calcula-se que, só em 2015, a Alemanha recebeu cerca de 3.500 solicitantes de refúgio LGBTI. (MAGALHÃES, 2016) Nesse sentido, foi criado em 2016 um centro de acolhida para receber essa população, que conta com cursos profissionalizantes e de alemão, grupos de apoio

Periódicus, Salvador, n. 12, v.1, nov.2019-abr.2020 - Revista de estudos indisciplinares em gêneros e sexualidades Publicação periódica vinculada ao Núcleo de Pesquisa NuCuS, da Universidade Federal da Bahia - UFBA ISSN: 2358-0844 - Endereço: http://www.portalseer.ufba.br/index.php/revistaperiodicus 
e de debates e consultas com médicos especializados, além de atendimento em diversos idiomas. (ABOUT..., 2016)

Outra iniciativa nesse sentido foi a criação da Casa Miga, primeiro abrigo para refugiados LGBTI do Brasil e localizada em Manaus, no estado do Amazonas. A casa foi inaugurada no final de 2018 e é administrada pela ONG Manifesta LGBT+ com o apoio do Acnur, além de receber doações e organizar diversos eventos para custear as despesas. Para Yelitza Ricardo, mulher lésbica de origem venezuelana, “aqui [na Casa miga] temos mais liberdade para sermos quem somos. Na Venezuela não podíamos demonstrar amor. Até nos abrigos sofremos preconceito de outros venezuelanos". (PRESTES, 2018)

Assim como o abrigo localizado em Berlim, a Casa Miga também conta com oficinas e cursos profissionalizantes. Esse tipo de iniciativa, portanto, serve não apenas como uma forma de livrar essas pessoas de mais um tipo de opressão - a de gênero -, mas também para integrá-las à sociedade local, com possibilidade de entrar no mercado de trabalho e desenvolver um novo idioma.

Na Espanha, a ONG Kifkif, membro da Federação Estatal de Lésbicas, Gays, Trans e Bissexuais, por meio de financiamento do Conselho de Políticas Sociais e Familiares da Comunidade de Madri, é responsável por um centro que abriga temporariamente indivíduos LGBTI, além de oferecer assessoria jurídica, programas de inclusão social (como grupos de apoio e aulas de castelhano) e serviços de saúde (como teste rápido para o vírus da imunodeficiência humana - HIV), entre outros tipos de orientação. (¿QUIÉNES..., 2019)

\section{Considerações finais}

O objetivo deste trabalho foi evidenciar os obstáculos encontrados pela população LGBTI não apenas em seus Estados de origem, mas ao longo do processo de migração forçada em busca de uma vida plena e segura. Não apenas a população local pode se mostrar um problema para essa categoria - visto que, além da xenofobia, em muitos casos ela não aceita sexualidades e identidades de gênero dissidentes -, mas também os próprios refugiados que não fazem parte desse grupo. Assim, esse cruzamento de diversos tipos de violência torna o processo migratório cada vez mais complexo e pode, de alguma forma, cercear a liberdade de quem não se identifica como heterossexual e/ou cisgênero.

Periódicus, Salvador, n. 12, v.1, nov.2019-abr.2020 - Revista de estudos indisciplinares em gêneros e sexualidades Publicação periódica vinculada ao Núcleo de Pesquisa NuCuS, da Universidade Federal da Bahia - UFBA ISSN: 2358-0844 - Endereço: http://www.portalseer.ufba.br/index.php/revistaperiodicus 
Uma das soluções encontradas por membros da sociedade civil foi a criação de abrigos voltados especificamente para a população LGBTI. Essa tendência, no entanto, ainda conta com pouco apoio do poder público, que acaba por transferir sua responsabilidade de proteger esses indivíduos para outras esferas.

Por fim, revela-se a necessidade de uma melhor compreensão acerca da dinâmica desses espaços, a fim mitigar possíveis deficiências e melhorar a vivência de seus hóspedes. Para tanto, faz-se necessária a presença dessas pessoas ao longo de todos os processos de tomada de decisão, pois, antes de tudo, são seres políticos e devem ter o direito de serem protegidos, acolhidos e integrados.

\section{Referências}

¿QUIÉNES somos? Kifkif, Madrid, 11 nov. 2017. Disponível em: https://bit.ly/2v0qDOt. Acesso em: 2 set. 2019.

ABOUT us. Schwulenberatung, Berlin, 18 jun. 2016. Disponível em: https://bit.1y/2R6h9tJ. Acesso em: 5 jun. 2019.

ALTO COMISSARIADO DAS NAÇÕES UNIDAS PARA OS REFUGIADOS. Diretrizes sobre proteção internacional $n^{\circ}$ 01: perseguição baseada no gênero, no contexto do artigo 1A(2) da Convenção de 1951 e/ou Protocolo de 1967 relativos ao Estatuto dos Refugiados, Genebra, 2002. Disponível em: https://bit.ly/2sB4VQf. Acesso em: 5 jun. 2019.

ALTO COMISSARIADO DAS NAÇÕES UNIDAS PARA OS REFUGIADOS. Guidance note on refugee claims relating to sexual orientation and gender identity, Geneva, 21 nov. 2008. Disponível em: https://bit.ly/2TD8qAM. Acesso em: 5 jun. 2019.

ALTO COMISSARIADO DAS NAÇÕES UNIDAS PARA OS REFUGIADOS. Trabalhando com lésbicas, gays, bissexuais, transexuais, travestis e intersex em deslocamento forçado. Genebra: Acnur, 2011. Guia básico 2. Divisão de Proteção Internacional. Disponível em: https://bit.ly/2G1aRVT. Acesso em: 5 jun. 2019.

ALTO COMISSARIADO DAS NAÇÕES UNIDAS PARA OS REFUGIADOS. Diretriz sobre proteção internacional $n^{\circ}$ 09, Genebra, 23 out. 2012. Disponível em: https://bit.ly/2NFlhyB. Acesso em: 5 jun. 2019.

ALTO COMISSARIADO DAS NAÇÕES UNIDAS PARA OS REFUGIADOS. Cartilha informativa sobre a proteção de pessoas refugiadas e solicitantes de refúgio LGBTI. Genebra: Acnur, 2018. Disponível em: https://bit.ly/2G5b0rf. Acesso em: 5 jun. 2019.

ALTO COMISSARIADO DAS NAÇÕES UNIDAS PARA OS REFUGIADOS. Global trends: forced displacement in 2018, Geneva, 19 jun. 2019. Disponível em: https://bit.ly/2G58PnL. Acesso em: 25 jun. 2019.

ANARTE, E. LGBTI: huir de Latinoamérica a un destino incierto. $D W$, Bonn, 15 ago. 2019. Disponível em: https://bit.ly/38ixQb6. Acesso em: 2 set. 2019.

ANDRADE, V. L. Migrações internas e internacionais motivadas por orientação sexual e identidade de gênero. Travessia - Revista do Migrante, São Paulo, v. 77, p. 1948, jul.-dez. 2015a. Dossiê Migração, Sexualidade e Identidade de Gênero.

Periódicus, Salvador, n. 12, v.1, nov.2019-abr.2020 - Revista de estudos indisciplinares em gêneros e sexualidades Publicação periódica vinculada ao Núcleo de Pesquisa NuCuS, da Universidade Federal da Bahia - UFBA ISSN: 2358-0844 - Endereço: http://www.portalseer.ufba.br/index.php/revistaperiodicus 
ANDRADE, V. L. Gays e lésbicas também (i)migram? Notas sobre refúgio por orientação sexual no Brasil. In: REUNIÓN DE ANTROPOLOGÍA DEL MERCOSUR, 11., 2015, Montevideo. Actas [...]. Montevideo: RAM, 2015b.

ANDRADE, V. L. Desafios no atendimento, acolhida e integração local de imigrantes e refugiados/as LGBTI. Cadernos ObMigra - Revista Migrações Internacionais, Brasília, v. 2, p. 1-34, 2016 a.

ANDRADE, V. L. Refúgio por orientação sexual no Brasil: perfil das solicitações nas cidades de Brasília/DF e São Paulo/SP. Revista do Núcleo de Estudos e Pesquisas em Gênero \& Direito, João Pessoa, v. 5, p. 1-24, 2016 b.

ANDRADE, V. L. Refugiados e refugiadas por orientação sexual no Brasil: dimensões jurídicas e sociais. In: SEMINÁRIO MIGRAÇÕES INTERNACIONAIS, REFÚGIOS E POLÍTICAS, 2016, São Paulo. Anais [...]. Campinas: Unicamp, 2016c. [17] p.

ANDRADE, V. L. Gay African refugees in Brazil: a diaspora? In: DIASPORAS: EXPLORING CRITICAL ISSUES, 8., 2016, Oxford. Conference papers [...]. Oxford: Mansfield College, 2016d. p. 86-91.

ANDRADE, V. L. Imigração e sexualidade: solicitantes de refúgio, refugiados e refugiadas por motivos de orientação sexual na cidade de São Paulo. 2017. 238 f. Dissertação (Mestrado em Antropologia Social) - Universidade Federal de Santa Catarina, Florianópolis, 2017. Disponível em: https://bit.ly/2TCy9t2. Acesso em: 5 jun. 2019.

ANSA. Itália concede refúgio a mulher trans brasileira, e diz que Brasil não é capaz de proteger pessoas LGBT. Metro Jornal, São Paulo, 15 maio 2019. Disponível em: https://bit.ly/378C2dp. Acesso em: 5 jun. 2019.

BARIFOUSE, R. STF aprova a criminalização da homofobia. BBC News, São Paulo, 13 jun. 2019. Disponível em: https://bbc.in/2tzmIYH. Acesso em: 25 jun. 2019.

BINNIE, J. The globalization of sexuality. London: Sage, 2004.

BOLSONARO diz em encontro com a imprensa que país não deve ser destino gay. Folha de S.Paulo, São Paulo, 25 abr. 2019. Disponível em: https://bit.ly/30JkSkh. Acesso em: 5 jun. 2019.

BUTLER, J. Problemas de gênero: feminismo e subversão da identidade. 8. ed. Rio de Janeiro: Civilização Brasileira, 2015. 287 p.

CASTLES, S. Entendendo a migração global: uma perspectiva desde a transformação social. Revista Interdisciplinar da Mobilidade Humana, Brasília, v. 18, n. 35, p. 11-43, 2010. Disponível em: https://bit.ly/3734u06. Acesso em: 5 jun. 2019.

CASTLES, S.; MILLER, M. La era de la migración: movimientos internacionales de población en el mundo moderno. Zacatecas: Universidad Autónoma de Zacatecas, 2004. Disponível em: https://bit.ly/30xcaoQ. Acesso em: 5 jun. 2019.

ERIBON, D. Reflexões sobre a questão gay. Rio de Janeiro: Companhia de Freud, 2008.

FÉLIX, J.; COSTA, E. Após ataques de brasileiros, 1,2 mil venezuelanos deixaram o país, diz Exército. G1, Boa Vista, 19 ago. 2018. Disponível em: https://glo.bo/2R4EITC. Acesso em: 5 jun. 2019.

FERNANDES, M. S. A concessão de refúgio a indivíduos LGBTI. Revista Diplomatize, João Pessoa, ano 2, n. 3, v. 2, p. 7-26, 2016.

FOUQUET, C. O imigrante alemão e seus descendentes no Brasil (1808-1824- 1974). São Paulo: Instituto Hans Staden; Federação dos Centros Culturais, 1974.

FRAIHA, B. S. P. Refúgio internacional de pessoas transexuais: análise do caso Maria Clara de Sena. 2018. Trabalho de Conclusão de Curso (Bacharelado em Direito) Centro Universitário do Estado do Pará, Belém, 2018. Disponível em: https://bit.ly/2R5RUrf. Acesso em: 5 jun. 2019. 
FRANÇA, I. Vivendo em liberdade? Homossexualidade, diferenças e desigualdades entre brasileiros na Espanha. Travessia - Revista do Migrante, São Paulo, n. 77, p. 1328, jul.-dez. 2015. Dossiê Migração, Sexualidade e Identidade de Gênero.

FRANÇA, I. L. "Refugiados LGBTI": direitos e narrativas entrecruzando gênero, sexualidade e violência. Cadernos Pagu, Campinas, v. 50, e175006, 2017. Disponível em: https://bit.ly/2R75M4U. Acesso em: 5 jun. 2019.

FRANÇA, I. L.; OLIVEIRA, M. P. Refugiados LGBTI: gênero e sexualidade na articulação com refúgio no contexto internacional de direitos. Travessia - Revista do Migrante, São Paulo, v. 29, p. 33-50, 2016.

FUNDACIÓN HUÉSPED. Ley de identidad de género y acceso al cuidado de la salud de las personas trans en Argentina. Buenos Aires: Fundación Huésped; ATTA, 2014. Disponível em: https://bit.ly/37a0Dyy. Acesso em: 5 jun. 2019.

GARDNER, C. V. Gender. In: GARDNER, C. V. Historical dictionary of feminist philosophy. Lanham: Scarecrow Press, 2006. p. 98-100.

JUBILUT, L. L.; APOLINÁRIO, S. M. O. S. A necessidade de proteção internacional no âmbito da migração. Revista Direito $G V$, São Paulo, v. 6, n. 1, p. 275-294, jan.-jun. 2010.

KOSER, K. International migration: a very short introduction. New York: Oxford University Press, 2007.

LA FOUNTAIN-STOKES, L. De sexilio(s) y diáspora(s) homosexual(es) latina(s): el caso de la cultura puertorriqueña y nuyorican queer. Debate Feminista, Ciudad de México, ano 15, v. 29, p. 138-157, 2004.

MAGALHÃES, G. Cidades alemãs criam rede de abrigos para homossexuais. $O$ Globo, Berlim, 2016. Disponível em: https://glo.bo/2RyWBsI. Acesso em: 5 jun. 2019.

MAGLIANO, M. J. Interseccionalidad y migraciones: potencialidades y desafíos. Estudos Feministas, Florianópolis, v. 23, n. 3, p. 691-712, 2015. Disponível em: https://bit.ly/369Dafk. Acesso em: 5 jun. 2019.

MENDES, V. A. Perseguição e refúgio LGBTI: a lei russa de censura às "formas não tradicionais de relação". 2016. Trabalho de Conclusão de Curso (Bacharelado em Relações Internacionais) - Universidade Católica de Santos, Santos, 2016.

MENDES, V. A. O caso da lei russa de censura LGBTI: uma análise amparada pelo direito internacional dos refugiados. São Paulo: Amazon, 2017.

MENDES, V. A.; GORISCH, P. O Brasil como Estado de origem para refugiados LGBTI: contradição entre âmbitos interno e externo. In: SEMINÁRIO DE RELAÇÕES INTERNACIONAIS DA ASSOCIAÇÃO BRASILEIRA DE RELAÇÕES INTERNACIONAIS - ABRI, 3., 2016, Florianópolis. Anais [...]. Florianópolis: UFSC, 2016a. p. 1-11.

MENDES, V. A.; GORISCH, P. É relevante falar do refúgio fundamentado pela orientação sexual e identidade de gênero? In: ENCONTRO DE PESQUISA EM RELAÇÕES INTERNACIONAIS - EPRI, 2016, Marília. Anais [...]. Marília: Unesp, 2016b. p. 1-15.

MENDES, V. A.; GORISCH, P. Os elementos de gênero e orientação sexual na convenção relativa ao Estatuto dos Refugiados de 1951 (com protocolo em 1967). In: SEMANA DE RELAÇÕES INTERNACIONAIS DA UNESP (DES)CONSTRUINDO AS RELAÇÕES INTERNACIONAIS: O MUNDO EM MOVIMENTO, 14., 2016, Franca. Anais [...]. Franca: Unesp, 2016c. [13] p.

MENDES, V. A.; GORISCH, P. Expressão da identidade sexual e a análise da credibilidade do pedido de refúgio fundamentado em razão da orientação sexual e identidade de gênero. In: SEMINÁRIO MIGRAÇÕES INTERNACIONAIS, REFÚGIOS E POLÍTICAS, 2016, São Paulo. Anais [...]. Campinas: Unicamp, 2016d. [13] p.

MOURATIAN, P. Ciudadania plena para todas y todos. In: ARGENTINA. Hacia una ley de identidad de género. Buenos Aires: Ministerio de Justicia y Derechos

Periódicus, Salvador, n. 12, v.1, nov.2019-abr.2020 - Revista de estudos indisciplinares em gêneros e sexualidades Publicação periódica vinculada ao Núcleo de Pesquisa NuCuS, da Universidade Federal da Bahia - UFBA ISSN: 2358-0844 - Endereço: http://www.portalseer.ufba.br/index.php/revistaperiodicus 
Humanos, 2011. p. 7-8. Disponível em: https://bit.ly/381D3Ph. Acesso em: 5 jun. 2019.

MULLER, F. Refugiados homossexuais: o Código Penal Iraniano e as violações ao Direito Internacional dos Direitos Humanos. 2012. Trabalho de Conclusão de Curso (Bacharelado em Relações Internacionais) - Universidade Federal de Santa Catarina, Florianópolis, 2012.

NASCIMENTO, D. A proteção de refugiados LGBTI no Direito Internacional. In: SIMPÓSIO INTERNACIONAL DIÁLOGOS NA CONTEMPORANEIDADE: TECNOCIÊNCIA, HUMANISMO E SOCIEDADE, 4., 2015, Lajeado. Anais [...]. Lajeado: Univates, 2015. p. 110-115.

NASCIMENTO, D. Identidades perseguidas: o critério de concessão de refúgio via pertença a grupo social. In: PEREZ, T. S. (org.). Encontro História \& Psicologia: dialogando relações de gênero. Porto Alegre: wwlivros, 2016. v. 1. p. 1-58.

NASCIMENTO, D. Refúgio LGBTI: panorama nacional e internacional. Porto Alegre: Editora Fi, 2018. 170 p.

OLIVA, T. Minorias sexuais enquanto "grupo social" e o reconhecimento do status de refugiado no Brasil. Brasília: Acnur Brasil, 2012.

ORGANIZAÇÃO DAS NAÇÕES UNIDAS. Assembleia Geral. Convenção relativa ao estatuto dos refugiados (1951). Genebra, 28 jul. 1951. Disponível em: https://bit.ly/38mFilq. Acesso em: 5 jun. 2019.

ORGANIZAÇÃO INTERNACIONAL PARA AS MIGRAÇÕES. La migración y los migrantes: características y cambios regionales. Informe sobre las migraciones en el mundo. Genebra: OIM, 2018. Disponível em: https://bit.ly/2NGux5Q. Acesso em: 5 jun. 2019.

PRESTES, M. Abrigo para refugiados venezuelanos LGBTI é inaugurado em Manaus. Folha de S.Paulo, São Paulo, 5 nov. 2018. Disponível em: https://bit.ly/2TElt5d. Acesso em: 5 jun. 2019.

REZENDE, Lucas Felicetti. Sexílio, alteridade e reconhecimento: uma análise teórica sobre o refúgio de LGBTs. O Social em Questão, Rio de Janeiro, ano 21, v. 41, p. 283-306, 2018. Disponível em: https://bit.ly/2tAVDnM. Acesso em: 5 jun. 2019.

SAFFIOTI, H. I. B. Gênero, patriarcado e violência. São Paulo: Editora Fundação Perseu Abramo, 2004a. 151 p.

SAFFIOTI, H. I. B. Diferença ou indiferença: gênero, raça/etnia, classe social. In: GODINHO, T.; SILVEIRA, M. L. (org.). Politicas públicas e igualdade de gênero. São Paulo: Coordenadoria Especial da Mulher, 2004b. p. 159-165.

SAFFIOTI, H. I. B.; MUÑOZ-VARGAS, M. Mulher brasileira é assim. Rio de Janeiro: Rosa dos Tempos, 1994. 283 p.

SANTOS, A. V. A concessão de refúgio a pessoas LGBT. Redoc, Rio de Janeiro, v. 3, n. 1, p. 177-197, 2019. Disponível em: https://bit.ly/2RyQS6e. Acesso em: 5 jun. 2019.

SILVA, D. Y. R. "Direitos iguais e com os mesmos nomes!": da ampliação do conceito de refugiado à população LGBT. In: REDIN, G.; MINCHOLA, L. A. B. (org.). Imigrantes no Brasil: proteção dos direitos humanos e perspectivas políticojurídicas. Curitiba: Juruá, 2015. p. 341-354.

SILVA, D. Y. R. "Transpondo fronteiras, re(existimos)!": refugiados LGBTIs no Canadá e no Brasil e o direito à identidade de gênero e à orientação sexual. Revista Novas Fronteiras, Porto Alegre, v. 3, p. 71-84, 2016.

SILVA, D. Y. R. Proteção internacional de LGBTIs refugiados no Brasil. 2017. Trabalho de Conclusão de Curso (Bacharelado em Relações Internacionais) - Universidade Federal de Santa Maria, Santa Maria, 2017.

SIN VIOLENCIA LGBTI. El prejuicio no conoce fronteras. Bogotá: AltaVoz Editores, 2019. Disponível em: https://bit.ly/30FnT4P. Acesso em: 2 set. 2019. 
SOBREIRA, F. M. Refugiados homossexuais no Brasil. 2014. Trabalho de Conclusão de Curso (Bacharelado em Relações Internacionais) - Pontifícia Universidade Católica de São Paulo, São Paulo, 2014.

SOBREIRA, F. M. Refugiados LGBTI no Brasil. Travessia - Revista do Migrante, São Paulo, v. 77, p. 49-65, jul.-dez. 2015.

THE INTERNATIONAL LESBIAN, GAY, BISEXUAL, TRANS AND INTERSEX ASSOCIATION. Sexual orientation laws in the world - 2019, Geneva, 20 mar. 2019. Disponível em: https://bit.ly/38nv44u. Acesso em: 5 jun. 2019.

THEODORO, H. G. S.; COGO, D. Fluxos migratórios, comunicação e cidadania: vivências de imigrantes LGBT na cidade de São Paulo. InTexto, Porto Alegre, v. 44, p. 57-73, jan.-abr. 2019. Disponível em: https://bit.ly/30CRigg. Acesso em: 5 jun. 2019.

TRANSGENDER EUROPE. Transrespect versus transphobia worldwide, Berlin, 6 jan. 2015. Disponível em: https://bit.ly/2sDk43y. Acesso em: 5 jun. 2019.

WIHTOL DE WENDEN, C. As novas migrações. Revista Sur, São Paulo, v. 13, n. 23, p. 17-28, 2016. Dossiê sobre Migrações e Direitos Humanos. Disponível em: https://bit.ly/2tB4PIO. Acesso em: 5 jun. 2019. 